\title{
The effect of shot peening on the fatigue strength of steel sheets
}

\author{
M. Śledź, F. Stachowicz*, W. Zielecki \\ Rzeszow University of Technology, Powst. Warszawy 12, Rzeszów 35-959, Poland
}

Received 4 April 2014, received in revised form 27 September 2014, accepted 7 October 2014

\begin{abstract}
In this study, the effect of shot peening on the fatigue strength of 1.8159, 1.4301 and 30HGSA steel sheets, which are used for a screen sieve plate, was investigated. During exploitation of the separating screener, some parts of the screen sieve plate situated near the fixed edge undergo the largest deformation caused by impact bending and need special treatment. One of the methods to enhance the fatigue strength of a material is shot peening. Experimental studies showed that this method visibly increased the fatigue strength limit, especially in the case of 30HGSA steel sheet.
\end{abstract}

K e y w o r d s: shot peening, fatigue strength, steel sheet

\section{Introduction}

In mechanical processing of granular materials, the basic process is screening [1], hence it is extremely important to have a suitable material for the screen sieve plate. Vibrating screen is widely used for grading and screening materials in the following fields: minerals, quarry, building materials, etc. Unfortunately, the parts of the screen sieve plate which are located near the fixed edge undergo the largest deformation, caused by impact bending during the separating screener exploitation. One of the methods to enhance the fatigue strength of the material used for the screen sieve is shot peening. Shot peening is one of the burnishing methods. It is widely used to improve the fatigue strength of the material through the creation of a compressive residual stress in its surface layers $[2,3]$. The compressive residual stress on the surface has the effect of increasing the fatigue strength of the sieve material, and therefore would be beneficial in reducing the possibility of fatigue damage. By shot peening, the surface layer of a material is caused to yield plastically under the impact of shot. Compressive residual stresses result from the inability of the plastically deformed material to reaccommodate itself on the elastic subsurface. Benefits due to shot peening are increase in resistance to fatigue, stress corrosion cracking, fretting, galling, erosion and closing of pores [4]. Depending on the character of the forces with which the tool acts on the machined surface, one distinguishes static and dynamic peening [5]. The tall orders of the burnishing process are materials with hardness above 45 HRC [1]. The experimental investigations show that the shot peening has the good influence on the fatigue strength of the constructional steels [2], spring steels $[4,6]$, titanium alloys [5]. The shot peening results depend on various parameters such as shot size, velocity, shape, material, coverage, hardness, intensity, etc. The shot peening results have been widely studied theoretically and experimentally $[2-7]$.

Application of the pneumatic shot peening process to ground surfaces may cause even elimination of subsequent polishing operation. The changes in the condition of the surface affected by pneumatic shot peening have a good influence on the fatigue parts executed for various materials. The pneumatic shot peening effectiveness was defined by increasing fatigue durability or permanent fatigue boundary and it depends on process parameters, a kind of treatment material and both thermal and mechanical treatment. The research conducted on the basis of the process of pneumatic shot peening has shown its great effectiveness when it comes to the fatigue of constructional steels about 10$40 \%$, titanium alloys about $10-20 \%$, steels with layers about $5-25 \%$ [8], spring steels about $30-40 \%$ [9]. The burnishing done by the pneumatic shot peening which has wrong parameters, does not guarantee the suitable properties, in fact, sometimes it might bring

*Corresponding author: tel.: (48 17) 8651538; fax: (48 17) 8543116; e-mail address: stafel@prz.edu.pl 
Table 1. Chemical compositions of the steels tested

\begin{tabular}{|c|c|c|c|c|c|c|c|c|c|}
\hline \multirow{2}{*}{ Material } & \multicolumn{9}{|c|}{ Chemical composition (wt.\%) } \\
\hline & $\mathrm{C}$ & $\mathrm{Mn}$ & $\mathrm{Si}$ & $\mathrm{S}$ & $\mathrm{P}$ & $\mathrm{Cr}$ & $\mathrm{Ni}$ & $\mathrm{Cu}$ & $\mathrm{V}$ \\
\hline 1.8159 & $0.46-0.54$ & $0.5-0.8$ & $0.15-0.40$ & $0.03 \max$ & $0.03 \max$ & $0.8-1.1$ & $0.4 \max$ & - & $0.1-0.2$ \\
\hline 1.4301 & $0.07 \max$ & $2.0 \max$ & $1.0 \max$ & $0.03 \max$ & $0.045 \max$ & $18-20 \max$ & $8-10 \max$ & - & - \\
\hline $30 \mathrm{HGSA}$ & $0.28-0.34$ & $0.8-1.1$ & $0.9-1.2$ & $0.025 \max$ & $0.025 \max$ & $0.8-1.1 \max$ & $0.3 \max$ & $0.3 \max$ & - \\
\hline
\end{tabular}

Table 2. Mechanical properties of the sheet metals tested before shot peening

\begin{tabular}{lccc}
\hline Sheet material & Yield stress $R_{\mathrm{p} 0.2 / \mathrm{eH} *}(\mathrm{MPa})$ & Ultimate strength $R_{\mathrm{m}}(\mathrm{MPa})$ & Total elongation $A_{50}$ \\
\hline 1.8159 & $212^{*}$ & 409 & 0.24 \\
1.4301 & 315 & 708 & 0.51 \\
$30 \mathrm{HGSA}$ & $377^{*}$ & 580 & 0.27 \\
\hline
\end{tabular}

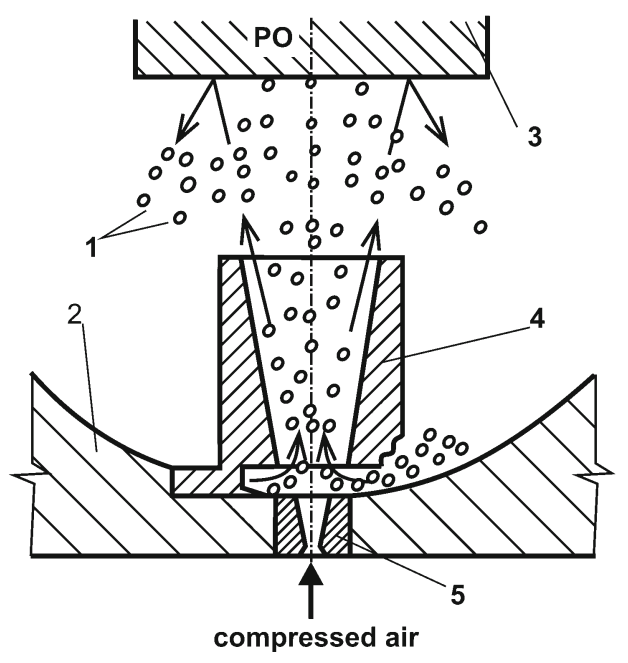

Fig. 1. Scheme of ejector nozzle and pneumatic shot peening: 1 - balls, 2 - working chamber bottom, 3 - workpiece, 4 - upper nozzle, 5 - lower nozzle.

some deteriorations. This is the main reason for which one should conduct the special research, the goal of which is to determine optimum parameters of pneumatic shot peening, which provide obtaining the best properties for each piece of a machine.

\section{Material and experimental procedure}

The procedure presents experimental investigations on the burnishing the particular parts of the machine, with the usage of the bearing balls with a diameter of $2 \mathrm{~mm}$, which are coated to the suitable speed limit, by the blast of compressed air. The pneumatic shot peening process was carried out using one or a few nozzles which consist of lower and upper nozzle (Fig. 1). The lower nozzle is usually installed directly on working chamber bottom and made in the form of de La Valla nozzle, supported by compressed air with pressure of $0.6 \mathrm{MPa}$. The nozzle task is to produce stream air with large linear velocity which captures balls from the chamber bottom and directs them through an upper nozzle on a workpiece. Balls bang on the reinforcement surface with the speed limit of $3-8 \mathrm{~m} \mathrm{~s}^{-1}$, and after the returning, they go down to the bottom of the chamber and then they are reused for the process of burnishing. During the process of burnishing the reinforced piece of the machine moves, which task is to provide the full coverage of the element with the signs of the treatment. Kinematics movements should make it possible to achieve $100 \%$ coverage of the workpiece. This process itself is affected by ejector nozzle geometry and ball diameter, air pressure, working nozzle to the workpiece and peening time.

The research was conducted on $1.0 \mathrm{~mm}$ sheet metal specimens made of three kinds of steels: 1.8159, 1.4301 and 30HGSA. The specimens were prepared in the rectangular shape of $110 \times 38.4 \mathrm{~mm}^{2}$ and were oriented in rolling directions of a sheet. The chemical composition of the steels is given in Table 1 and the mechanical properties are provided in Table 2. The surface of the specimens was subjected to pneumatic shot peening. The 3D geometrical profile of specimen surface was examined using the optical Talysurf CCI Litle profilometer. Research on the fatigue was conducted on the special test stand which was built on the basis of the Wöhler type testing machine ETS SOLUTION L Series MPA 102-L620M at a frequency of 300 cycles $\mathrm{s}^{-1}$. During the investigation the specimen was placed in the hydraulic handle (Fig. 2) which has a constant strength of interlocking and can lead to the resonance vibration. The specimen undergoes vibration until the cracking and/or gaining final number of cycles. During the research there were $2 \times 10^{6}$ accepted cycles. 


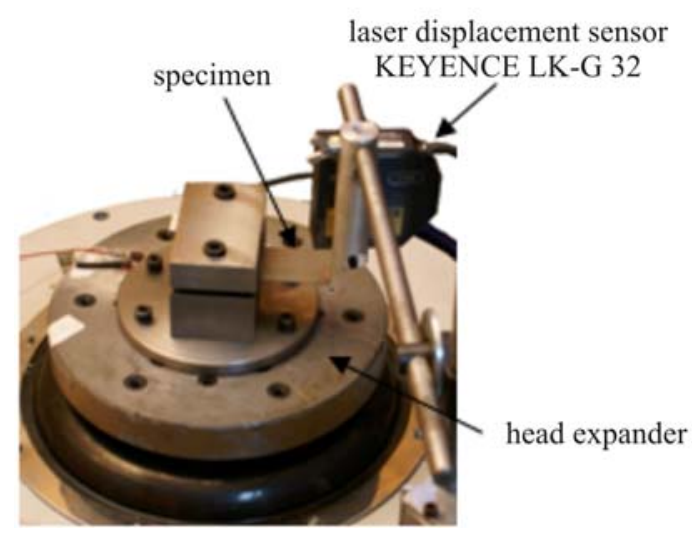

Fig. 2. Vibratory stand used for fatigue test.

\section{Results and discussion}

As a result of pneumatic shot peening the surface of the sheet specimen visibly differs from virgin surface and it is covered with small dimples (Fig. 3). During shot peening process only plastic deformation of asperities takes place and any changes of material microstructure in the rest of specimen material have not been observed [8, 9]. From many the ISO 25178 international standard surface texture parameters, only two elements of the feature parameters (Sda and $\mathrm{Sp}$ ) which can be connected with fatigue strength will be analyzed in this paper. The ratio of closed dales area Sda to the maximum peak height para-

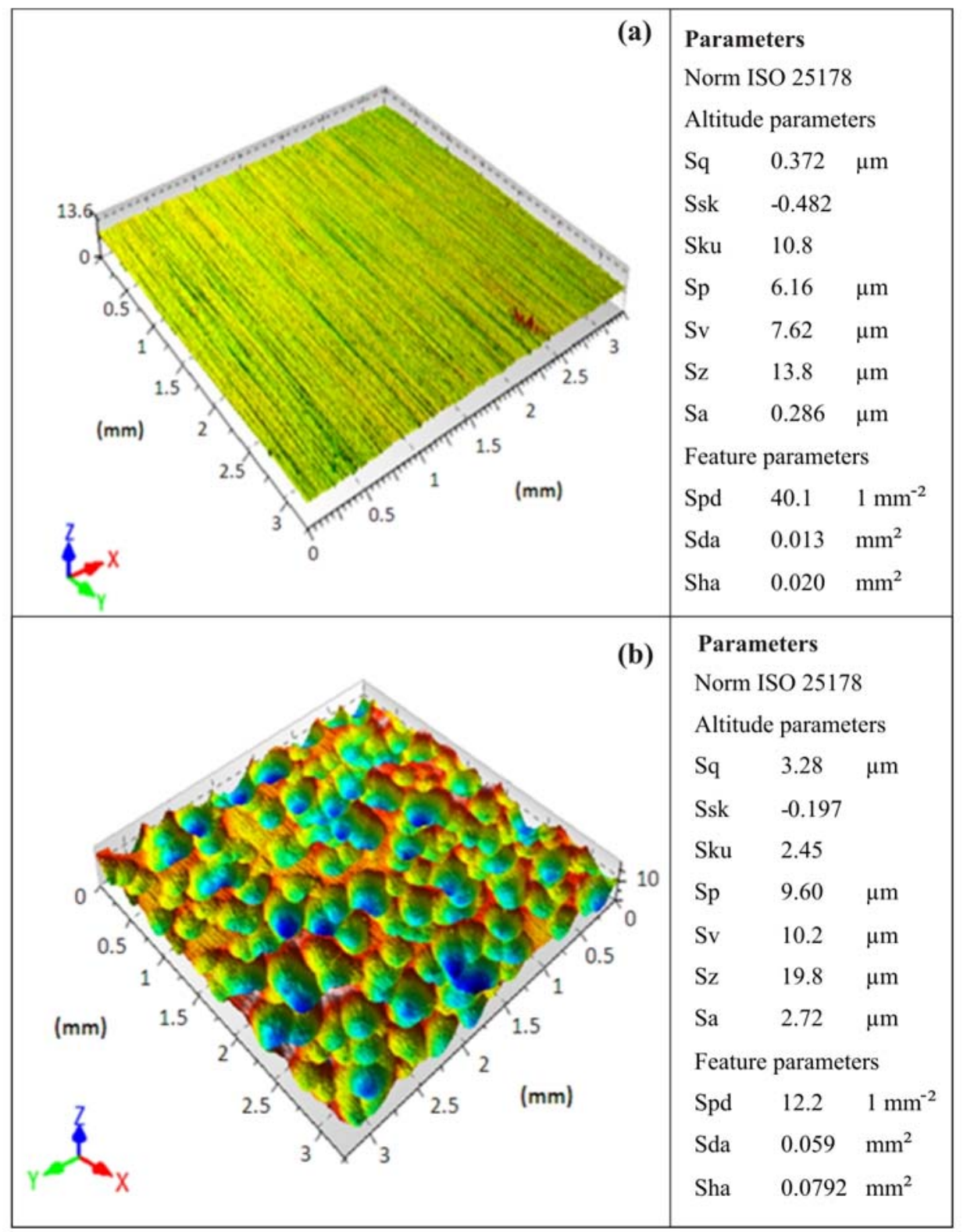

Fig. 3. Surface topography of the 1.8159 steel sheet before (a) and after (b) pneumatic shot peening. 


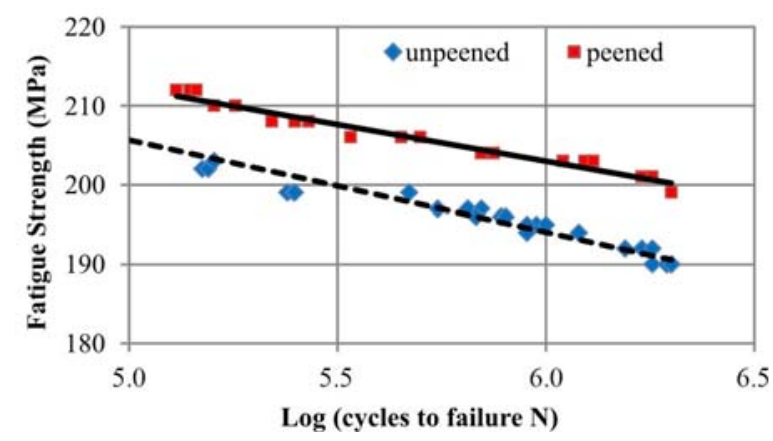

Fig. 4. Effect of shot peening on fatigue strength of the 30HGSA steel sheet.

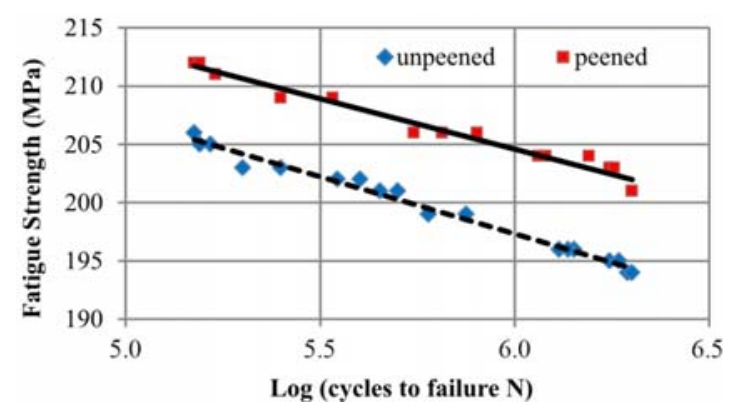

Fig. 5. Effect of shot peening on fatigue strength of the 1.4301 steel sheet.

meter Sp

$$
\zeta=\mathrm{Sda} / \mathrm{Sp}^{2}
$$

is proposed as a fatigue strength index, under assumption that larger value of $\zeta$-index indicates better fatigue strength of a material.

The value of closed dales area (Sda) for peened 1.8159 steel sheet specimens increased by 4.54 times in comparison to that of unpeened specimens while the value of maximum peak height parameter (Sp) for peened specimens increased by 1.56 times in comparison to that of unpeened specimens (Fig. 3). After simple calculations it was determined that shot peening has positive effect on fatigue strength since the value of $\zeta=640.2$ for peened specimens is nearly two times larger in comparison with the value of $\zeta=342.6$ for unpeened specimens.

Results of the bending fatigue in the form of $S-N$ curves (Figs. 4-6) visibly demonstrate beneficial effect of shot peening. Fatigue strength of peened specimens increased by $2-5 \%$ in comparison to that of unpeened specimens. The 30HGSA constructional steel is the best, from the all steel sheets tested, for hardening under shot peening since fatigue strength of its peened specimens increased by $5 \%$ in comparison to that of unpeened specimens (Fig. 4). For comparison, fatigue

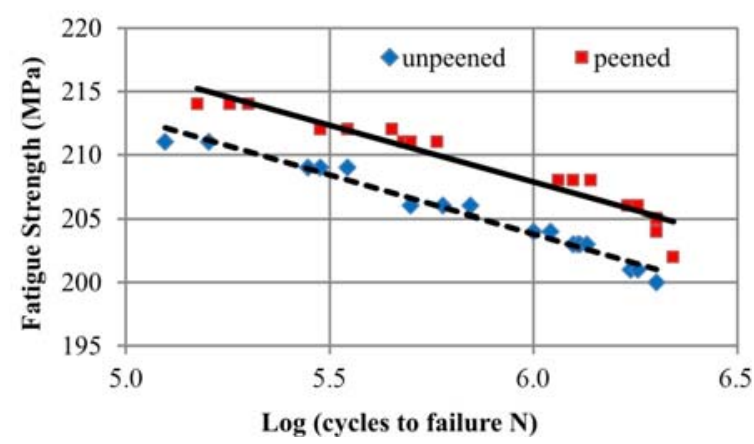

Fig. 6. Effect of shot peening on fatigue strength of the 1.8159 steel sheet.

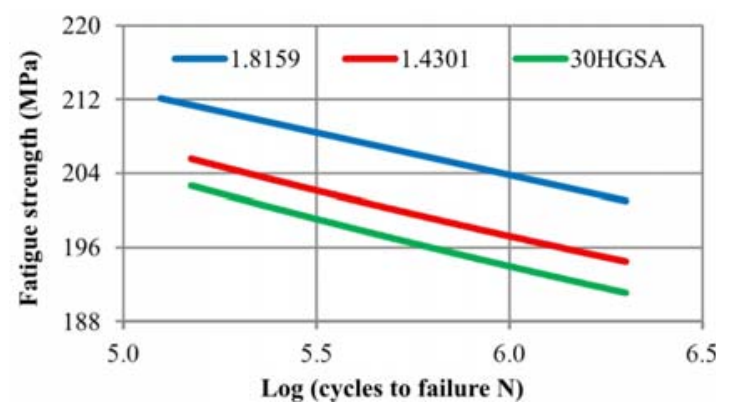

Fig. 7. Comparison of the $S$ - $N$ curves for all unpeened specimens.

strength of the 1.4301 austenitic chromium-nickel steel increased by $3 \%$ (Fig. 5) and of the 1.8159 spring steel increased by $2 \%$ (Fig. 6). The effect of shot peening is more visible when fatigue life is taken into account. It was determined that at stress level $S=205 \mathrm{MPa}$ shot peening of sheet specimens resulted in increase of failure cycles value:

- 30HGSA steel: 7.1 times - from 86000 cycles for unpeened to 610000 cycles for peened specimens,

- 1.4031 steel: 5.4 times - from 165000 cycles for unpeened to 894000 cycles for peened specimens,

- 1.8159 steel: 3.4 times - from 744000 cycles for unpeened to 2540000 cycles for peened specimens.

Comparison of the results of the rotating bending fatigue $S$ - $N$ curves for three kinds of steel sheets before and after shot peening (Figs. 7,8 ) has shown that:

- there is larger difference in $S-N$ curves for unpeened specimens,

- the position of $S$ - $N$ curve of unpeened 1.8159 steel sheet specimen is close to the position of $S$ - $N$ curve of peened 30HGSA steel sheet specimen,

- the best material for screener sieve is the 1.8159 spring steel.

\section{Conclusions}

The influence of a shot peening treatment on the bending fatigue strength of 1.4301, 1.8159 and 


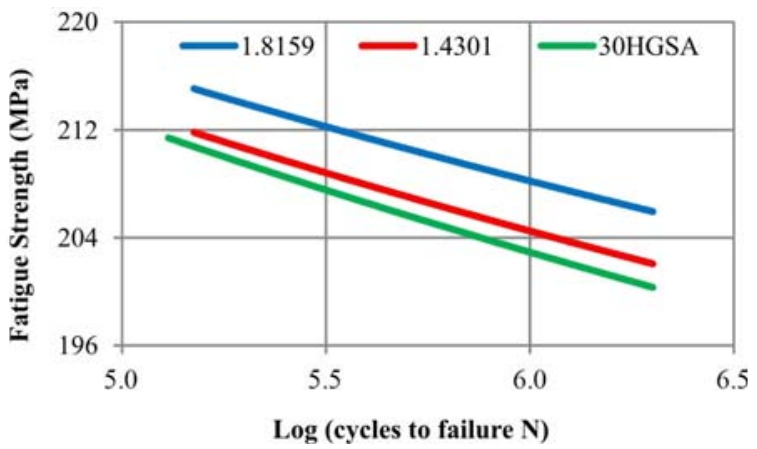

Fig. 8. Comparison of the $S$ - $N$ curves for all peened specimens.

30HGSA steel sheets has been investigated. Results of the bending fatigue in the form of $S$ - $N$ curves visibly demonstrate beneficial effect of shot peening, especially in the case of the 30HGSA steel sheet. Thus, the use of shot peening of sheet surface made it possible to increase the fatigue life of screener sieve. The comparative studies of fatigue strength have shown that the best material for screener sieve plate is 1.8159 spring steel.

\section{Acknowledgements}

This work was supported by the European Research Agency - FP7-PEOPLE-2011-IAPP - grant agree- ment No. 284544. Experiments were performed using aperture completed thanks to financial support of the POPW 01.03.00-18-012/09-00 and UDA-RPPK.01.03.00$-18-003 / 10$ projects co-financed by the European Union from the European Regional Development Fund for the years 2007-2013.

\section{References}

[1] Przybylski, W.: Burnishing Processing Technology. Warszawa, WNT 1987 (in Polish).

[2] Torres, M. A. S., Voorwald, H. J. C.: Int. J. Fatigue, 24, 2002, p. 877. doi:10.1016/S0142-1123(01)00205-5

[3] Tekeli, S.: Mater. Letters, 57, 2002, p. 604. doi:10.1016/S0167-577X(02)00838-8

[4] Gao, Y. K., Lu, F., Yin, Y. F., Yao, M.: Mater. Sci. Technol., 14, 2003, p. 372. doi:10.1179/026708303225010650

[5] Aggarwal, M. L., Agrawal, V. P., Khan, R. A.: Int. J. Fatigue, 28, 2006, p. 1845. doi:10.1016/i.ijfatigue.2005.12.004

[6] Zaleski, K.: Maintenance Reliability, 4, 2009, p. 65.

[7] Bagherifard, S., Ghelichi, R., Gaugliano, M.: Appl. Surface Sci., 258, 2012, p. 6831. doi:10.1016/i.apsusc.2012.03.111

[8] Zielecki, W.: ZN PRz, Mechanika, 22, 1990, p. 59.

[9] Zielecki, W.: ZN PRz, Mechanika, 14, 1987, p. 35. 